\title{
Distinct sperm nucleus behaviors between genotypic and temperature-dependent sex determination males are associated with replication and expression-related pathways in a gynogenetic fish
}

Yao-Jun Zhu ${ }^{1+}$, Xi-Yin $\mathrm{Li}^{1+}$, Jun Zhang ${ }^{1}$, Zhi Li ${ }^{1}$, Miao Ding ${ }^{1}$, Xiao-Juan Zhang ${ }^{1}$, Li Zhou ${ }^{1}$ and Jian-Fang Gui ${ }^{1} 2^{*}$ (D)

\begin{abstract}
Background: Coexistence and transition of diverse sex determination strategies have been revealed in some ectothermic species, but the variation between males caused by different sex determination strategies and the underlying mechanism remain unclear. Here, we used the gynogenetic gibel carp (Carassius gibelio) with both genotypic sex determination (GSD) and temperature-dependent sex determination (TSD) strategies to illustrate this issue.

Results: We found out that males of GSD and TSD in gibel carp had similar morphology, testicular histology, sperm structure and sperm vitality. However, when maternal individuals were mated with males of GSD, sperm nucleus swelling and fusing with the female pronucleus were observed in the fertilized eggs. On the contrary, when maternal individuals were mated with males of TSD, sperm nucleus remained in the condensed status throughout the whole process. Subsequently, semen proteomics analysis unveiled that DNA replication and gene expression-related pathways were inhibited in the sperm from males of TSD compared to males of GSD, and most differentially expressed proteins associated with DNA replication, transcription and translation were down-regulated. Moreover, via BrdU incorporation and immunofluorescence detection, male nucleus replication was revealed to be present in the fertilized eggs by the sperm from males of GSD, but absent in the fertilized eggs by the sperm from males of TSD.

Conclusions: These findings indicate that DNA replication and gene expression-related pathways are associated with the distinct sperm nucleus development behaviors in fertilized eggs in response to the sperm from males of GSD and TSD. And this study is the first attempt to screen the differences between males determined via GSD and TSD in gynogenetic species, which might give a hint for understanding evolutionary adaption of diverse sex determination mechanisms in unisexual vertebrates.
\end{abstract}

Keywords: Genotypic sex determination, Temperature-dependent sex determination, Semen proteomics, Gynogenesis

\footnotetext{
* Correspondence: jfgui@ihb.ac.cn

†Yao-Jun Zhu and Xi-Yin Li contributed equally to this work.

'State Key Laboratory of Freshwater Ecology and Biotechnology, Institute of Hydrobiology, The Innovative Academy of Seed Design, Chinese Academy of Sciences, University of Chinese Academy of Sciences, Wuhan 430072, China ${ }^{2}$ Institute of Hydrobiology, Chinese Academy of Sciences, Wuhan 430072, China
}

(c) The Author(s). 2018 Open Access This article is distributed under the terms of the Creative Commons Attribution 4.0 International License (http://creativecommons.org/licenses/by/4.0/), which permits unrestricted use, distribution, and reproduction in any medium, provided you give appropriate credit to the original author(s) and the source, provide a link to the Creative Commons license, and indicate if changes were made. The Creative Commons Public Domain Dedication waiver (http://creativecommons.org/publicdomain/zero/1.0/) applies to the data made available in this article, unless otherwise stated. 


\section{Background}

Sex determination is amazingly plastic in vertebrates, and two kinds of contrasting strategies including genotypic sex determination (GSD) and environmental sex determination (ESD) have been extensively revealed [1-3]. The primary sex of individuals with GSD is determined at the moment of fertilization via genotypic elements with sex difference [4], and diverse systems of GSD have been identified such as male heterogametic XX/XY system, female heterogametic $\mathrm{ZZ/ZW}$ system and their numerous variants [1]. While individuals with ESD do not have genetic difference between sexes, and their sex is determined during development [4] via environmental factors including temperature [5], photoperiod [6], social factors [7], $\mathrm{pH}$ and dissolved oxygen (DO) [8]. These two seemingly distinct sex determination strategies are not mutually exclusive, and coexistence, interaction and transition of GSD and ESD have been observed in fishes $[9,10]$, amphibians [11] and reptiles [5]. Along with genomic anatomy and investigation of non-model organisms, diverse sex determination systems and evolutionary mechanisms of transition among sex determination systems have been unveiled gradually $[1,2,5]$, but the variation within a sex between different sex determination strategies and the underlying mechanism remain unclear.

Gibel carp (Carassius gibelio) with a wide geographic distribution in Eurasian continent and neighboring islands [12-14], has two rounds of polyploidy origins including an ancient allopolyploidy and a recent autopolyploidy [13, 15]. Compared with other unisexual vertebrates [16], rare but significant male incidences were observed in many natural habitats $[9,17,18]$ of gibel carp with unisexual gynogenetic ability $[17,19,20]$. Recently, both GSD and temperature-dependent sex determination (TSD) were found to coexist in gibel carp through analyses of natural populations and lab experimental progenies [9, 21]. Moreover, extra microchromosomes and high temperature were illustrated to play genotypic and environmental male determination role respectively $[9,21]$, and a possible association between sex determination mechanisms and reproduction modes were revealed [9]. Diverse sex determination mechanisms of GSD and TSD $[9,21]$ and dual reproduction modes including unisexual gynogenesis and sexual reproduction [17, 19, 20] make gibel carp an ideal system to investigate plastic sex determination strategies and their evolutionary consequences.

Here, we observed that there were no significant masculine characteristic differences between males of GSD and TSD in morphology and histology, and their sperms also had similar structure and vitality. However, distinct sperm nucleus development behaviors were revealed from the fertilized eggs by two kind sperms of GSD males and TSD males. Subsequently, we performed iTRAQ-based quantitative proteomics analyses of semen samples between GSD and TSD males. Compared to males of GSD, pathways assigned to DNA replication, transcription and translation were illustrated to be down-regulated in the sperm from males of TSD. Moreover, male nucleus replication was only revealed in the eggs fertilized by the sperm from males of GSD, while no male nucleus replication was detected in the eggs fertilized by the sperm from males of TSD, via BrdU incorporation and immunofluorescence detection. These results indicated that distinct sperm nucleus development behaviors between males of GSD and TSD were associated with DNA replication and gene expression-related pathways in gibel carp.

\section{Results}

Similar morphological masculine characteristics between males of GSD and TSD

Males of gibel carp are able to be determined via both genotypic extra microchromosomes and larval rearing temperature, respectively $[9,21]$. So males of GSD with the genotypic male-specific marker (MSM) $[9,21]$ could be generated via sexual reproduction under normal rearing temperature at about $20{ }^{\circ} \mathrm{C}$ (Fig. 1a), while males of TSD without MSM [9] could be produced through high rearing temperature treatment $\left(32{ }^{\circ} \mathrm{C}\right)$ of gynogenetic larvae (Fig. 1b). Through comparative investigation, we found out that both males of GSD and males of TSD showed normal male secondary sex characteristics during breeding season, such as slender body shape (Fig. 1c and i), pearl organs on gill cover (Fig. 1d and j) and prolate anus (Fig. 1e and k). Moreover, mature testis (Fig. 1f and l) with spermatogenic cysts (Fig. $1 \mathrm{~g}$ and $\mathrm{m}$ ) and numerous sperms (Fig. $1 \mathrm{~h}$ and $\mathrm{n}$ ) were also observed in both males of GSD and TSD.

\section{Similar sperm morphology, structure, vitality, and hatchability}

To reveal similarities and differences between the sperm from males of GSD and TSD, we firstly examined the sperm morphology under scanning electron microscope (SEM) and both types of sperm had normal morphology that a flagellum came from the basal body (Fig. 2a and d). The sperm structure with nucleus $(\mathrm{N})$, mid-piece $(\mathrm{M})$ and flagellum (F) were observed (Fig. 2b and e), and the flagellum composed of 9 doublet microtubules and 2 central microtubules were also detected in both males of GSD and TSD (Fig. 2c and f) under transmission electron microscopy (TEM). Moreover, sperm head width and sperm tail length were $2.34 \pm 0.02 \mu \mathrm{m}$ and $45.44 \pm 0.55 \mu \mathrm{m}$ in males of GSD as well as $2.29 \pm 0.02 \mu \mathrm{m}$ and $46.03 \pm$ $0.61 \mu \mathrm{m}$ in males of TSD, respectively (T-test: $P=0.10$ and $P=0.48$, respectively) (Fig. $2 \mathrm{~g}$ ). Subsequently, to unveil sperm vitality, we analyzed average path velocity (VAP) $(82.52 \pm 2.39 \mu \mathrm{m} / \mathrm{sec})$, straight-line velocity (VSL) $(73.84 \pm 2.66 \mu \mathrm{m} / \mathrm{sec})$ and curvilinear velocity (VCL) $(88.26 \pm 2.50 \mu \mathrm{m} / \mathrm{sec})$ of sperm from males of GSD, which were not significantly different from the VAP (77.23 \pm $2.07 \mu \mathrm{m} / \mathrm{sec})$, VSL $(69.56 \pm 1.91 \mu \mathrm{m} / \mathrm{sec})$ and VCL $(83.25$ 

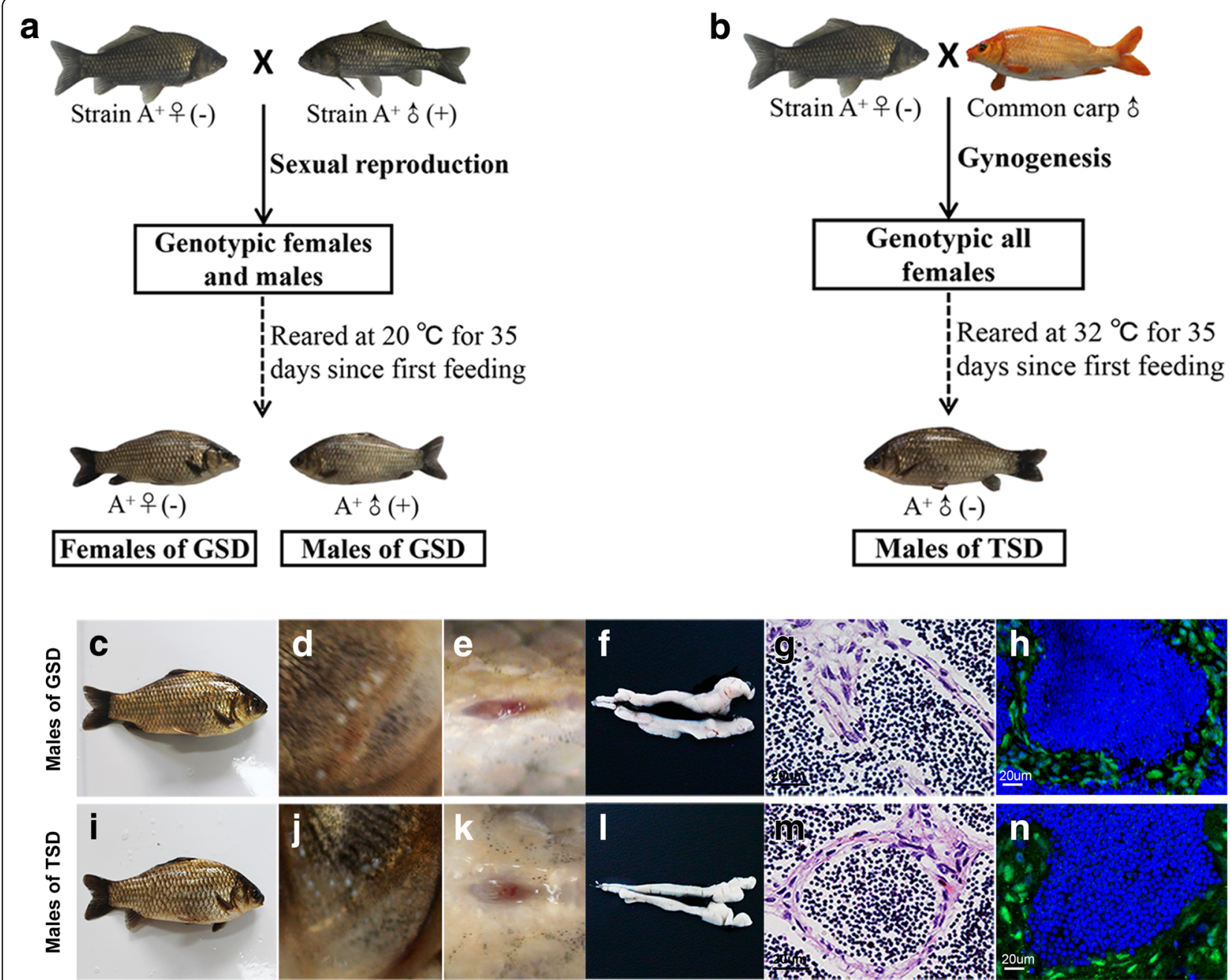

Fig. 1 Cultivation, morphology and testicular histology of males determined via GSD and TSD. a Cultivation of males determined via GSD. $\mathbf{b}$ Cultivation of males determined via TSD. c-n Morphological masculine characteristics and testicular histology between males of GSD and TSD. $\mathbf{c}, \mathbf{i}$ Body shape. $\mathbf{d}, \mathbf{j}$ Gill cover. e, $\mathbf{k}$ Anus. $\mathbf{f}$, I Testes. $\mathbf{g}, \mathbf{m}$ Haematoxylin-eosin staining of testes. $\mathbf{h}, \mathbf{n}$ Immunofluorescence staining of testes via CgVasa antibody. ㅇ: female; ô: male; (+): with male-specific marker (MSM); (-): without MSM

$\pm 1.98 \mu \mathrm{m} / \mathrm{sec}$ ) of sperm from males of TSD (T-test: $P=$ $0.10, P=0.19$ and $P=0.12$, respectively) (Fig. 2h). Besides, there were also no significant differences on hatchability between eggs fertilized by the sperm from males of GSD $(59 \% \pm 23 \%)$ and TSD $(68 \% \pm 17 \%)$ (T-test: $P=0.76)$. These results indicate that there are no significant differences in sperm morphology, structure, vitality, and hatchability between males of GSD and TSD.

\section{Different male incidence}

Although there were many similarities between males of GSD and TSD, male incidences in the offspring were revealed to be distinct between these two types of males. When the maternal fish from strain $\mathrm{A}^{+}$were mated with males of GSD from strain $\mathrm{A}^{+}, 34.9 \%( \pm 18.1 \%)$ males were detected in the offspring, and the MSM [21] was present in all sampled males and the paternal individuals, whereas it was absent in all randomly picked females and the maternal individuals (Fig. 3a and Additional file 1: Table S1). However, when maternal fish were mated with males of TSD from strain $\mathrm{A}^{+}$, no male offspring was generated and the MSM was absent in all randomly picked females and the parental individuals (Fig. $3 \mathrm{~b}$ and Additional file 1: Table S1), which were identical to the gynogenetic families (Fig. 3c and Additional file 1: Table S1). The similar results were also revealed previously in the wild population sampled from Poyang Lake in China [9].

\section{Distinct sperm nucleus events and development} behaviors

Moreover, differential male nucleus events and development behaviors were also revealed from the fertilized eggs 


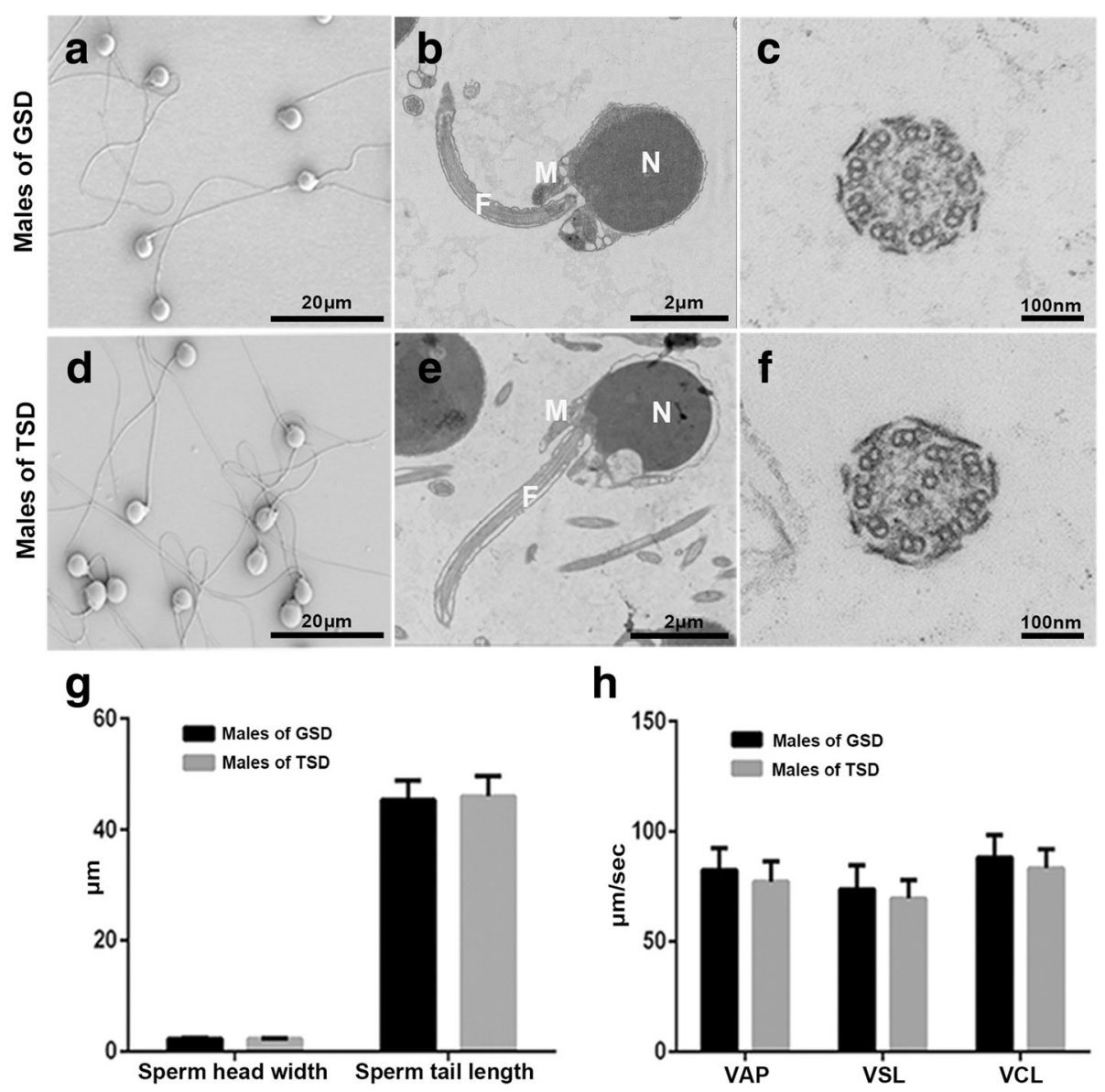

Fig. 2 Comparisons of sperm structure, size and vitality between males of GSD and TSD. SEM (a, $\mathbf{d})$ and TEM (b, $\mathbf{c}, \mathbf{e}, \mathbf{f})$ analysis of sperm from males of GSD and TSD. N: nucleus; M: mid-piece; F: flagellum. $\mathbf{g}$ Statistical data of sperm head width and sperm tail length. $\mathbf{h}$ Statistical data of sperm vitality. VAP: average path velocity, VSL: straight-line velocity, VCL: curvilinear velocity. Vertical bars: standard deviation

in response to the sperm from males of GSD and TSD. When the eggs of maternal fish were fertilized by the sperm from males of GSD, the fertilized egg encountered similar sexual reproduction events and behaviors, including sperm nucleus swelling, male pronucleus fusing with female pronucleus before $33 \mathrm{~min}$, even though male pronucleus did not completely integrate into the first mitosis after $35 \mathrm{~min}$ (Fig. 4a). However, when the eggs of maternal fish were fertilized by the sperm from males of TSD, the entered sperm nucleus was always preserved in the condensed status throughout the whole first mitosis process (Fig. 4b), which was identical to a typical process of gynogenesis stimulated by heterologous sperm from common carp (Fig. 4c). The data indicate that there exist distinct sperm nucleus events and development behaviors in the fertilized eggs between GSD and TSD males, in which the sperm of GSD males undergoes sperm nucleus swelling and pronucleus fusing similar to sexual reproduction, whereas the sperm of TSD males only triggers a typical unisexual gynogenesis.

\section{Comparative semen proteomics and differentially} expressed protein identification

To reveal the underlying molecular mechanism of differential sperm nucleus development behaviors in the fertilized eggs, iTRAQ-based quantitative semen proteomics were performed on three semen samples from three males of GSD and three semen samples from three males of TSD respectively. A total of 13,722 unique peptides and 3948 proteins were identified from 389,273 spectra (Fig. 5a and Additional file 2: Table S2). Subsequently, 99.2\% (3916 proteins) of these proteins were annotated via any of the 6 databases including non-redundant protein (NR), Swiss-Prot, Translated EMBL Nucleotide Sequence Data Library (TrEMBL), Clusters of Orthologous Groups of proteins (COG), Gene Ontology (GO) and Kyoto Encyclopedia of Genes and Genomes (KEGG) (Fig. 5b and Additional file 2: Table S2). In the KEGG classification, 3436 proteins were mapped to 44 terms belonged to 6 main categories (Fig. 5c). The pathway with most annotated proteins was "global and overview maps" (739 proteins), followed by 


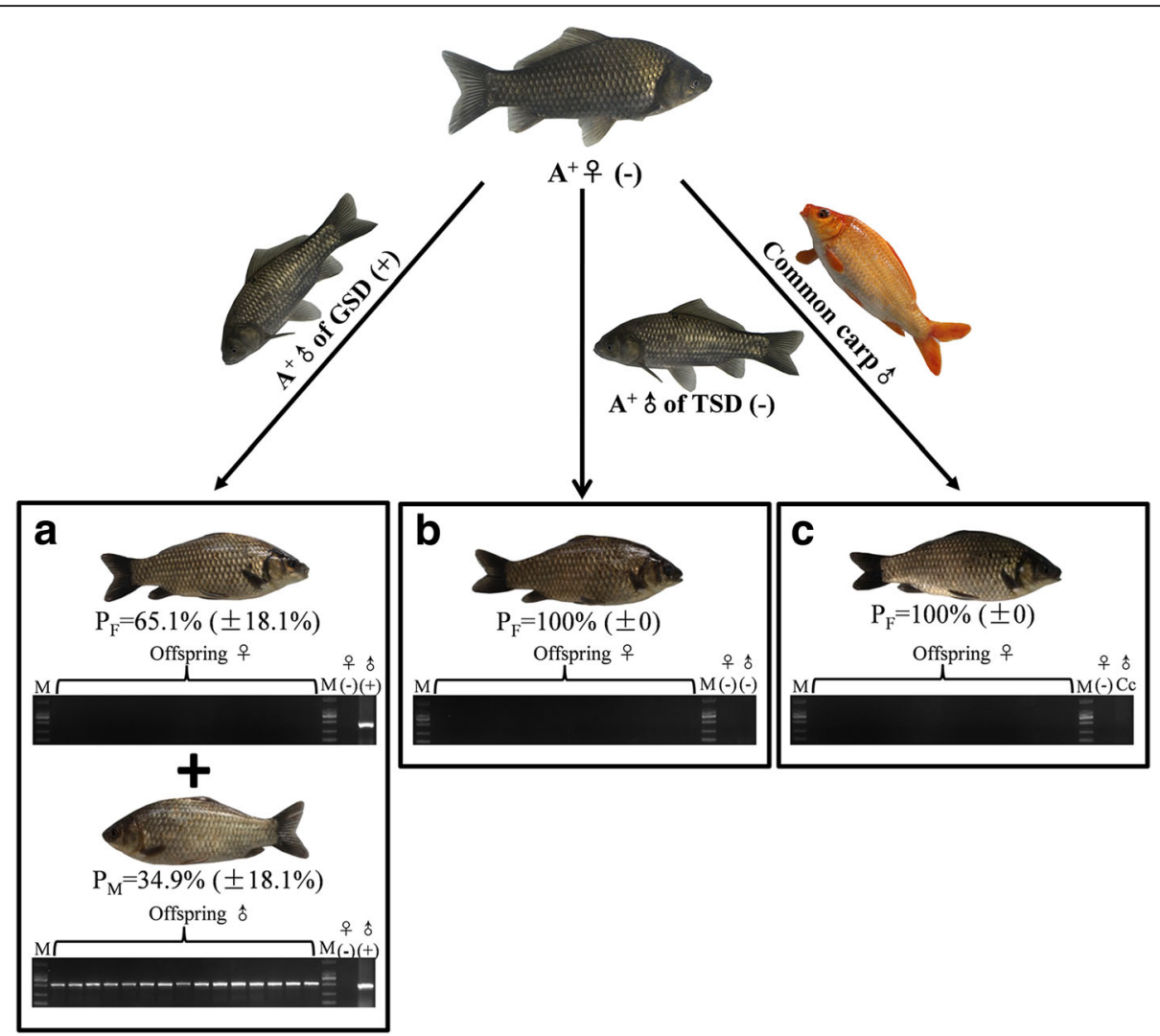

Fig. 3 Male incidence in the offspring. The maternal individuals from strain $A^{+}$were mated with males of GSD (a), males of TSD (b) and another species common carp (c). PCR detection analysis of MSM in the randomly-picked offspring and the parental individuals was shown at the bottom. ㅇ: female; Ô: male; (+): with MSM; (-): without MSM; $P_{M}$ : male proportion; $P_{F}$ : female proportion; Cc: Common carp; M: DL2000 marker. Detail data of replicates are given in additional file 1: Table S1

"signal transduction" (375 proteins), "folding, sorting and degradation" (320 proteins), "transport and catabolism" (295 proteins), and so on. Besides, 1972 proteins were classified into 24 COG terms, such as "general function prediction only", "posttranslational modification, protein turnover, chaperones", "energy production and conversion", "replication, recombination and repair" and so on (Fig. 5d). And 2345 proteins were classified into $57 \mathrm{GO}$ terms, and "cellular process", "cell" and "catalytic activity" were dominant in the category of "biological process", "cellular component" and "molecular function", respectively (Fig. 5e). Compared to semen proteomics from males of GSD, 753 differentially expressed proteins(DEPs)were identified (fold change $>1.2$, $P<0.05)$ in semen proteomics from males of TSD, including 310 up-regulated DEPs (Additional file 3: Table S3) and 443 down-regulated DEPs (Additional file 4: Table S4).

\section{Revelation of differentially regulated pathway}

To identify the biological pathways that might be differentially expressed in the semen between males of TSD and GSD, all the DEPs were used to performed overrepresentation analysis via Reactome database [22-25], only "DNA replication" and "Metabolism of RNA" were revealed to be down-regulated pathways based on $P<0.01$ and the False Discovery Rate $(\mathrm{FDR})<0.25 \quad[22,26]$. And, all 3 sub-pathways assigned to the pathway of "DNA replication", such as "M/G1 transition", "Synthesis of DNA" and "Regulation of DNA replication", were detected as down-regulated sub-pathways (FDR $=0.12,0.12$ and 0.13 , respectively). And, two sub-pathways in the pathway of "Metabolism of RNA", such as "Processing of capped intron-containing pre-mRNA" and "Regulation of mRNA stability by proteins that bind AU-rich elements", were illustrated to be down-regulated (FDR $=0.003$ and 0.13 , respectively) (Fig. 6a).

Subsequently, pathway enrichment analysis revealed that these 753 DEPs were mapped to 275 pathways through KEGG classification, and the top 20 enriched pathways were showed in Fig. 6b. Among the top 20 enriched pathways, the process of "Replication and repair" contained the most pathways, such as "Fanconi anemia pathway", "Non-homologous end-joining", "Base excision repair" and "DNA replication" (Fig. 6b and Additional file 5: Table S5), and the process of "Translation" had three enriched pathways including "Ribosome biogenesis in eukaryotes", "Ribosome" and "mRNA surveillance pathway", while the pathway of "Spliceosome" belonged to the 


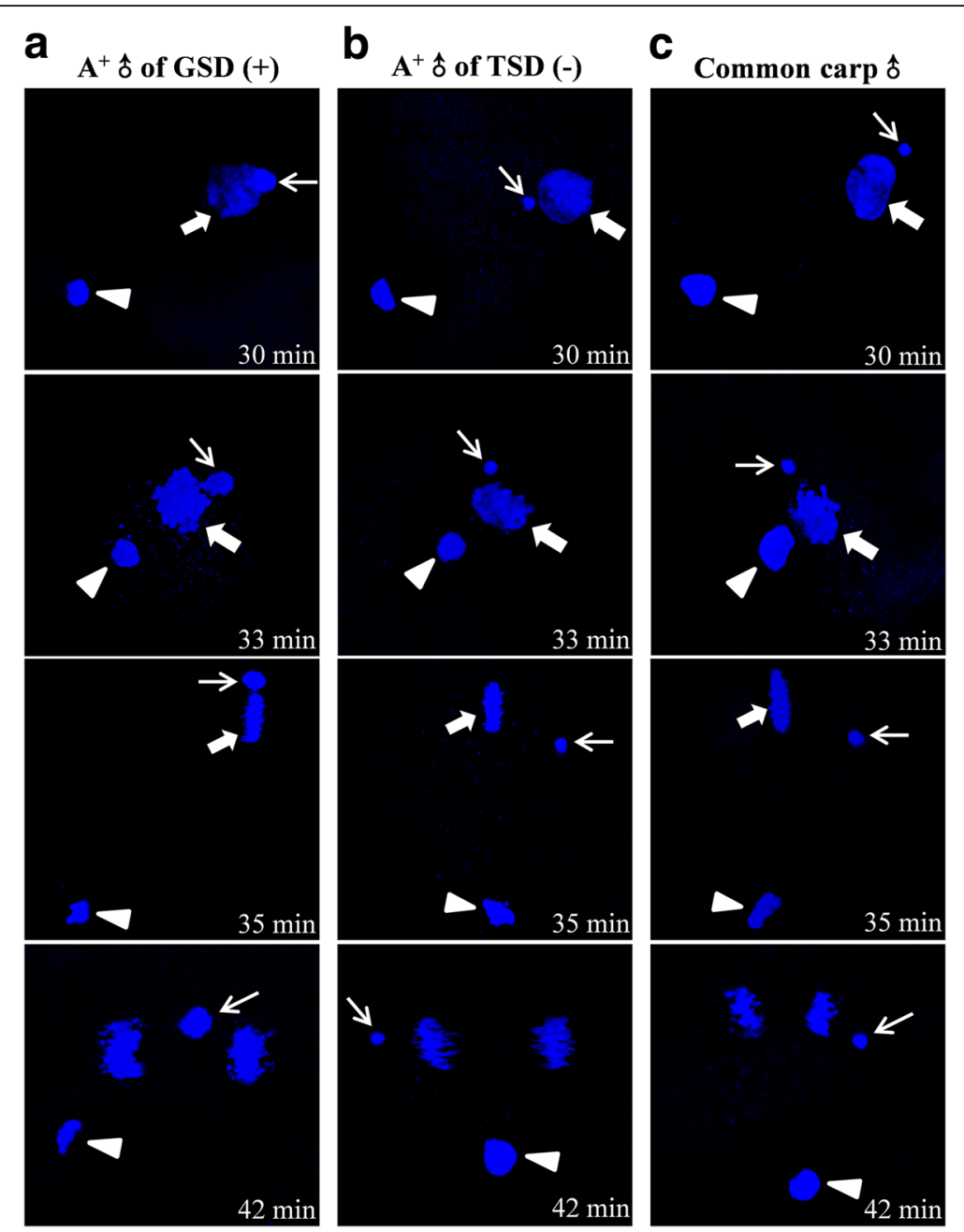

Fig. 4 DAPI-stained differential male nucleus behaviors in fertilized eggs. The fertilized eggs of strain $\mathrm{A}^{+}$inseminated by the sperms from males of GSD (a), males of TSD (b) and another species common carp (c). Thin arrows indicate sperm nucleus or male pronucleus. Thick arrows indicate female pronucleus. Arrowheads indicate second polar-body. Time showed on the right corner is the corresponding time after fertilization

process of "Transcription" had the most DEPs (Fig. 6b and Additional file 5: Table S5).

In the process of "Replication and repair", a total of 27 DEPs were identified to include 24 (88.9\%) down-regulated DEPs and 3 (11.1\%) up-regulated DEPs. There were 10, 9, $8,5,5,5$ and 4 down-regulated DEPs in the pathway of "Base excision repair", "DNA replication", "Fanconi anemia pathway", "Nucleotide excision repair", "Homologous recombination", "Non-homologous end-joining" and "Mismatch repair" respectively, while only 2, 1 and 1 up-regulated DEPs were identified in the pathway of "DNA replication", "Fanconi anemia pathway" and "Nucleotide excision repair" respectively (Fig. $6 \mathrm{c}$ and Additional file 6: Table S6). The process of "Translation" contains 41 (87.2\%) down-regulated DEPs and 6 (12.8\%) up-regulated DEPs. There were 18, 15, 9, 7 and 2 down-regulated DEPs in the pathway of "RNA transport", "Ribosome", "mRNA surveillance pathway", "Ribosome biogenesis in eukaryotes" and
"Aminoacyl-tRNA biosynthesis" respectively, while only 3, 1, 1 and 2 up-regulated DEPs were detected in the pathway of "RNA transport", "Ribosome", "mRNA surveillance pathway" and "Aminoacyl-tRNA biosynthesis" respectively (Fig. 6d and Additional file 7: Table S7). And 35 DEPs were identified in the process of "Transcription" to include 32 (91.4\%) down-regulated DEPs and 3 (8.6\%) up-regulated DEPs. There were 30, 1 and 1 down-regulated DEPs in the pathway of "Spliceosome", "RNA polymerase" and "Basal transcription factors" respectively, while only 3 up-regulated DEPs were revealed in the pathway of "Spliceosome" (Fig. 6e and Additional file 8: Table S8). Thus, most DEPs associated with "Replication and repair", "Translation" and "Transcription" were down-regulated in the semen from males of TSD compared with males of GSD, which was consistent with the results of overrepresentation analysis via Reactome database (Fig. 6a). 
a

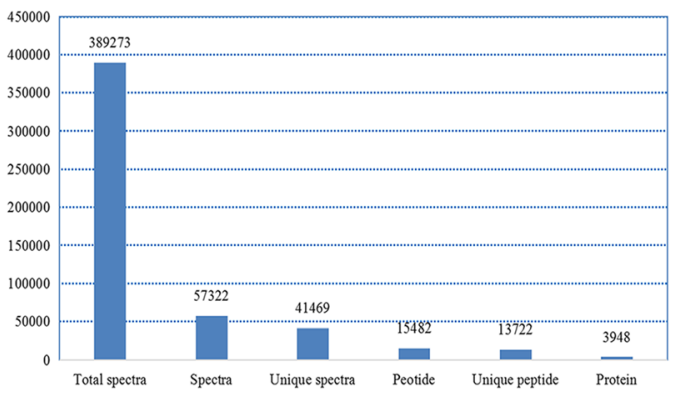

b

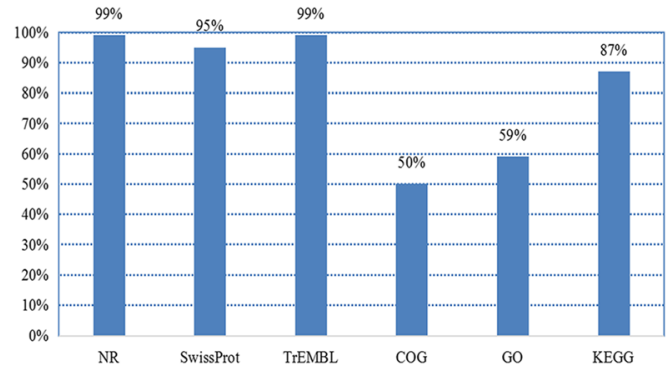

C

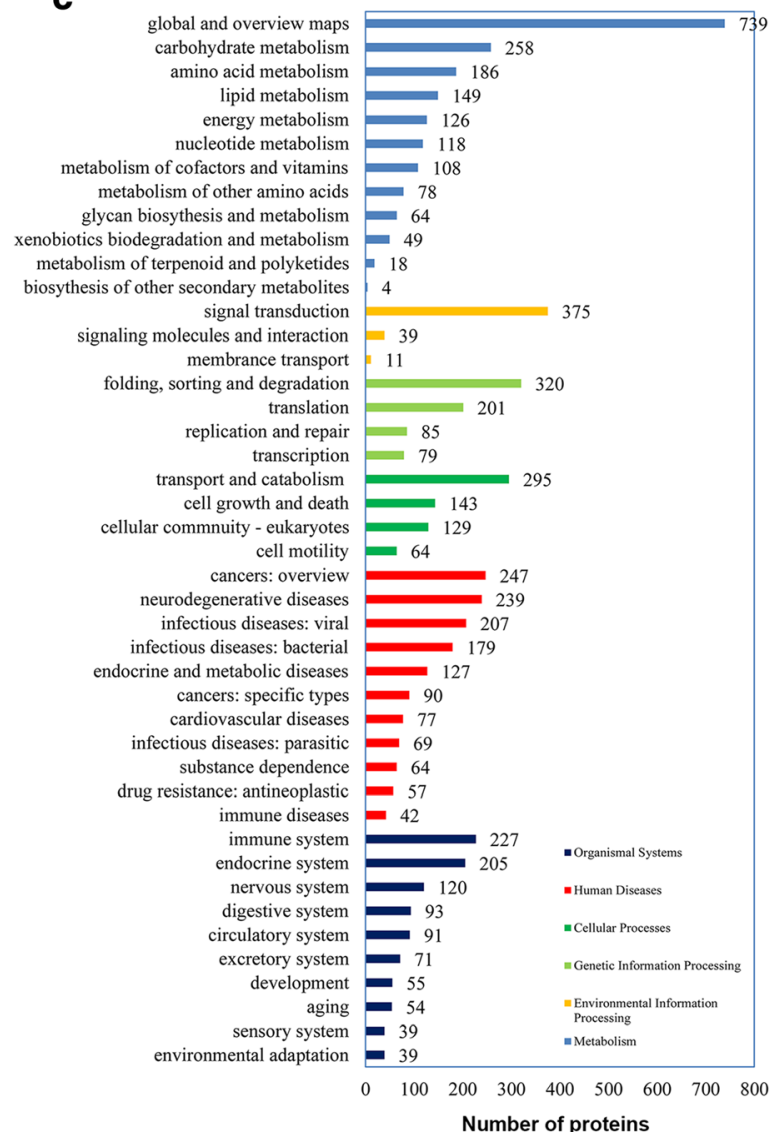

d

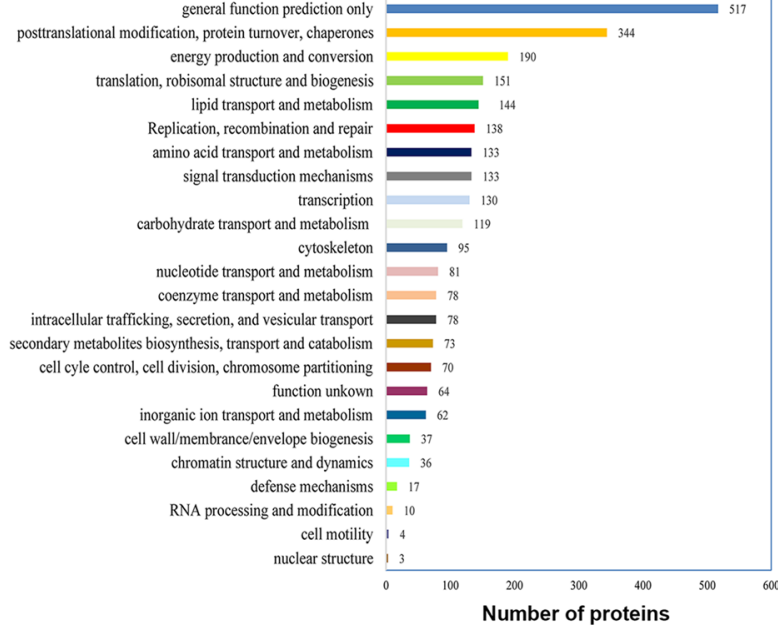

e
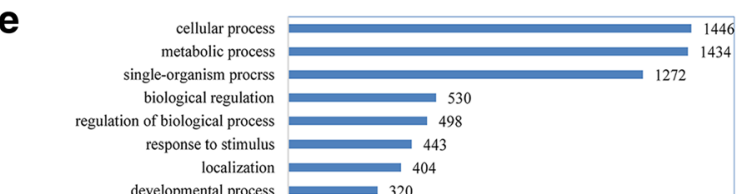

530
of biological process

response to stimulus 443

localization 404

developmental process 320

cellular component organization biogenesis $\quad 305$

$\begin{array}{rr}\text { multicellular organismal process } & 303 \\ \text { signaling } & 258\end{array}$

$\begin{aligned} \text { signaling } & \\ \text { negative regulation of biological process } & 141\end{aligned}$

positive regulation of biological process -122

immune system process $=70$

multi-orgianism process $=65$

locomotion $=54$

growth $=42$

biological adhesion = 31

reproduction $=30$

reproductive process "| 18

biological phase I 15

behavior I 11

\begin{tabular}{l|l} 
one secretion & 5
\end{tabular}

$\begin{array}{ll}\text { cell killing } & 4\end{array}$

rhythmic process

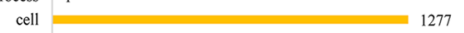

cell part

organelle

organelle part

membrance

cular complex

membrance part

-177
-50

extrellular region

\begin{tabular}{c|c} 
region part & 16 \\
synapse & 15
\end{tabular}

\begin{tabular}{r|r} 
synapse & 15 \\
cell junction & 13
\end{tabular}

cell junction 13

$\begin{array}{rll}\text { synapse part } & 10 \\ \text { nucleoid } & 4\end{array}$

nucleoid 4

collagen trimer 3

\begin{tabular}{l|l} 
extracellular matrix & 1
\end{tabular}

catalytic activity
binding

binding

transporter activity 124

enzyme regulator activity $=73$

structural molecule activity $=68$

electron carrier activity $=51$

molecular transducer activity = 33

\begin{tabular}{r|l} 
receptor activity & 18 \\
antioxidant activity & 17
\end{tabular}

protein binding transcription factor activity | 16

ucleic acid binding transcription factor activity 18

\begin{tabular}{r|r|} 
nucleic acid binding transcription factor activity & 1 \\
channel regulator activity & 5
\end{tabular}

\begin{tabular}{r|r|} 
guanyl-nucleotide exchange factor activity & 4 \\
translation regulator activity & 3
\end{tabular}

\begin{tabular}{c|c} 
translation regulator activity & 3 \\
metallochaperone activity & 1
\end{tabular}

metallochaperone activity 1

Biological Process

w Cellular Component

- Molecular Function

$\begin{array}{lllllllll}0 & 200 & 400 & 600 & 800 & 1000 & 1200 & 1400 & 1600\end{array}$

Number of proteins

Fig. 5 Summary information of semen proteomics. a Statistics of semen proteomic sequencing. b Overview of unigene/contig annotation in 6 databases including NR, Swiss-Prot, TrEMBL, COG, GO and KEGG. c Histogram of KEGG classification. d Histogram of COG classification. e Histogram of GO classification 


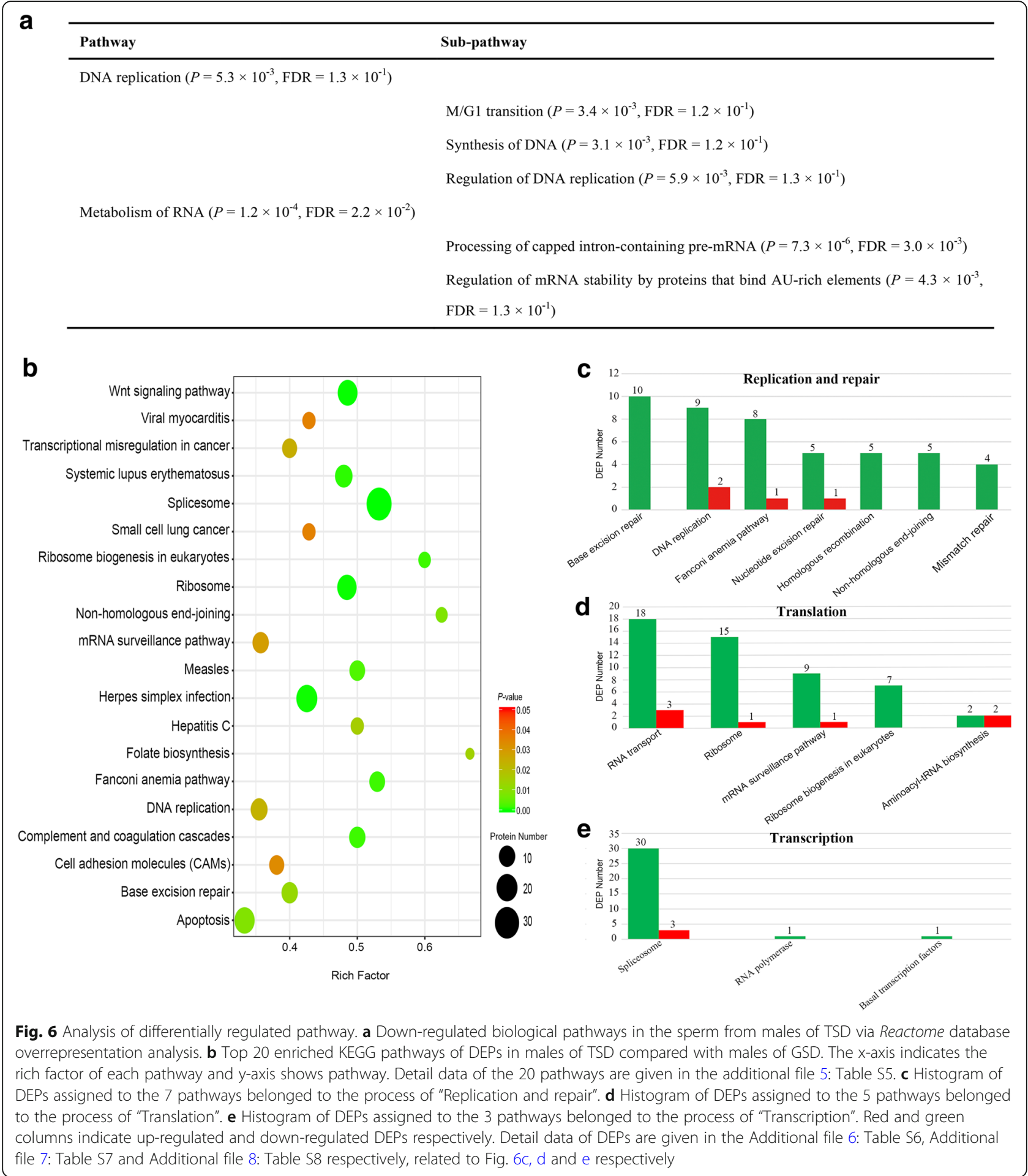

Although many proteins have been identified from the seminal plasma in rainbow trout (Oncorhynchus mykiss) [27] and common carp (Cyprinus carpio) [28], the proteins involved in the DNA replication and gene expression were detected only in sperm proteins instead of the seminal plasma proteins [29]. And all down-regulated DEPs assigned to "Replication and repair", "Translation" and "Transcription" had intracellular distributions (Additional file 9: Table S9), which indicated that these DEPs in semen were identified from sperm proteins. These findings suggest that most of the DNA replication and gene expression-related proteins should be disturbed in the sperm from males of TSD compared to 
males of GSD. Thereby, we propose a hypothesis that DNA replication, translation and transcription-related pathways might be associated with the distinct sperm nucleus behaviors between males of GSD and TSD.

\section{Confirmation of sperm nucleus replication difference}

To confirm the association between DNA replication and sperm nucleus development behaviors in the fertilized eggs, we used BrdU incorporation and immunofluorescence detection to trace DNA replication status as described previously [19]. When the eggs of maternal fish were fertilized by the sperm from males of GSD, both female and male nucleus experienced DNA replication as they migrated and contacted with each other. And the replicating pronuclei combined and formed zygote nucleus from 30 to $33 \mathrm{~min}$, even though the replicated male chromatin bubble was divorced from the maternal chromosomes at $35 \mathrm{~min}$ and failed to integrate into the first zygotic mitosis at $42 \mathrm{~min}$ (Fig. 7a). However, when the eggs of the same maternal fish were fertilized by the sperm from males of TSD, no DNA replication signal of male nucleus was observed during the whole first mitosis, and only female pronucleus underwent genome replication and completed the first cleavage (Fig. 7b), which was identical to the typical gynogenetic process (Fig. 7c). And the absence of male nucleus replication in the fertilized eggs by the males of TSD might be associated with down-regulation of DNA replication proteins in the semen from males of TSD compared to males of GSD.

\section{Discussion}

In this study, gibel carp males of genotypic and temperature-dependent sex determination were produced via sexual reproduction under normal rearing temperature and through high rearing temperature treatment of gynogenetic larvae, respectively. And males of GSD and TSD had similar morphology, testis histology, and sperm structure

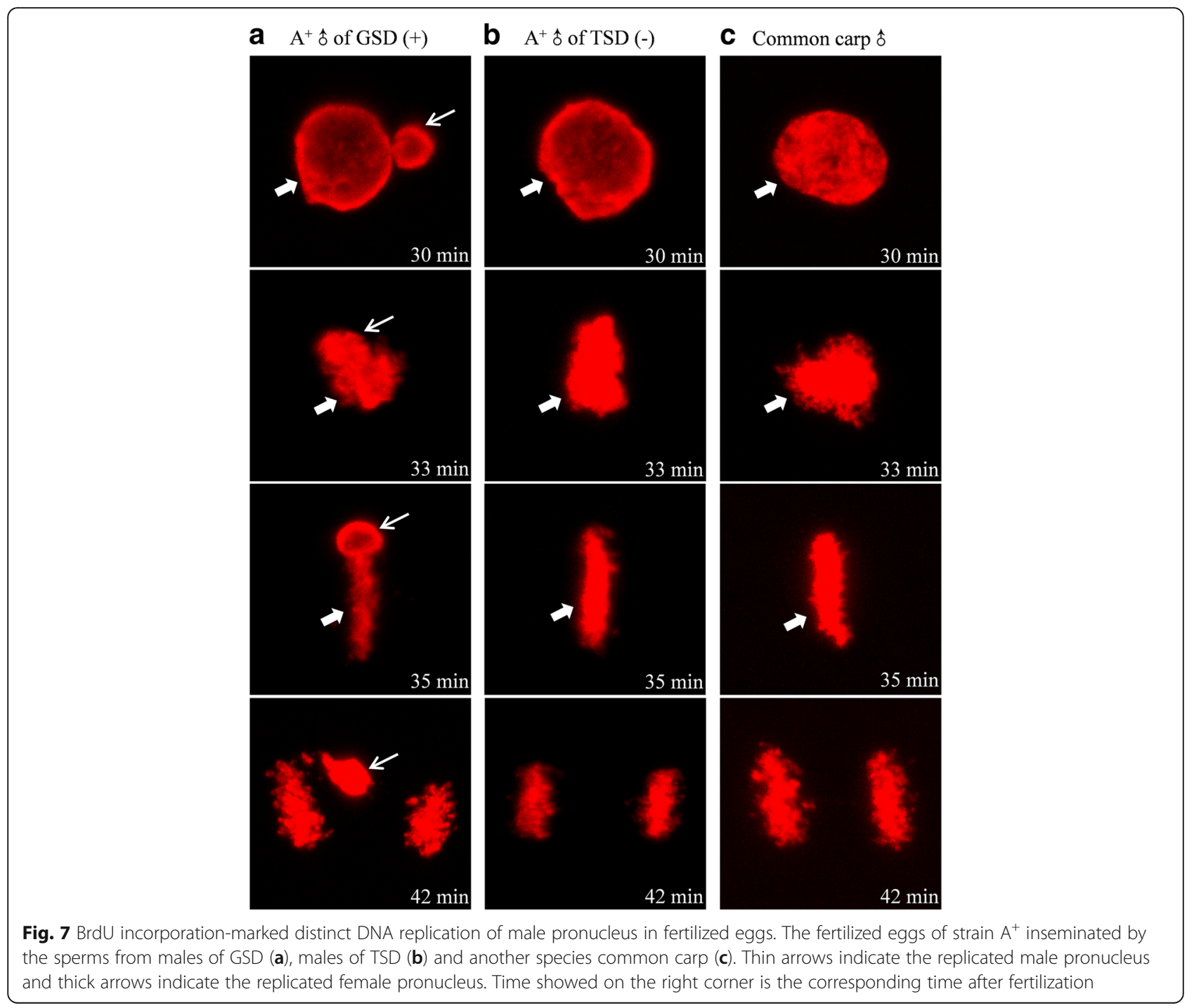


and sperm vitality. However, presence and absence of male nucleus swelling were observed in the fertilized eggs in response to the sperm from males of GSD and TSD, respectively. Subsequently, semen proteomics analysis revealed that DNA replication and gene expression-related pathways were down-regulated in the semen from males of TSD, compared to males of GSD. And the sperm from males of TSD was illustrated to have lower expression of most DEPs associated with DNA replication, transcription and translation than the sperm from males of GSD. Besides, male nucleus replication was only observed in the fertilized eggs by the sperm from males of GSD, which was not detected in the eggs fertilized by the sperm from males of TSD.

When the sperm from males of GSD fertilized the eggs of maternal gibel carp, sperm nucleus swelling was correlated with sperm nucleus replication (Fig. 4a and 7a). Meanwhile, when the sperm from males of TSD fertilized the eggs of maternal gibel carp, sperm nucleus without swelling was associated with absence of sperm nucleus replication (Fig. $4 \mathrm{~b}$ and $7 \mathrm{~b}$ ). These results indicated that male nucleus swelling is closely related with the DNA replication of male nucleus. On the other hand, most proteins of the pathways assigned to DNA replication were revealed to be down-regulated in the sperm from males of TSD, compared to the males of GSD (Fig. 6). In Caenorhabditis elegans, DNA replication initiation was also reported to trigger rapid decondensation of chromatids during the first embryonic mitosis after fertilization [30]. Therefore, we deduce that down-regulation of DNA replication-related proteins in the sperm from males of TSD might be associated with the absence of male nucleus replication and swelling in the fertilized eggs in response to the sperm from males of TSD.

In overrepresentation analysis via Reactome database, the pathway of "Metabolism of RNA" was also illustrated to be down-regulated except the pathway of "DNA replication" (Fig. 6a). And in the top 20 enriched KEGG pathways, the pathways belonged to "Translation" and "Transcription" were also down-regulated (Fig. 6b, d and e), which indicated that not only DNA replication-related pathway proteins were down-regulated, but also gene expression-related pathway proteins were inhibited in the sperm form males of TSD compared to males of GSD. In addition, most DEPs that are assigned to "Replication and repair", "Transcription" and "Translation" are connected in the interaction network analysis (Fig. 8). Thus, down-regulation of gene expression-related proteins might be also associated with absence of male nucleus replication and swelling in the fertilized eggs by the sperm from males of TSD, though DNA replication was deduced to be critical to distinct male nucleus behaviors between males of TSD and GSD as discussed above.

Although sperm nucleus without replication and swelling were both observed in the fertilized eggs in response to the sperm from gibel carp males of TSD (Fig. 4b and 7b) and the heterologous sperm from common carp (Fig. 4c and 7c), the potential mechanisms might be different from each other. In many bisexual species, sperm nucleus swelling and replication were not species-specific, even between species with far relationship [31-34]. Previous investigations revealed that common carp sperm swelled and formed pronuclei obviously in the common carp egg extracts [35], and hybrids were easily produced between common carp males and other bisexual fish species [33, 34]. However, common carp sperm were not able to swell and form pronuclei in the gibel carp extracts [35], and a typical process of gynogenesis stimulated by the heterologous sperm was observed when maternal gibel carp were mated with common carp [19]. Thus, the condensation status of common carp sperm in the eggs of gibel carp might be caused by the inhibition from gibel carp eggs instead of common carp sperm per se.

Gynogenetic gibel carp has two rounds of polyploidy origins. The first polyploidy event might result in ancestral tetraploid Carassius auratus $[15,36]$ and the late round of multiple independent polyploidy events from sympatric tetraploid $C$. auratus might lead to the extant hexaploid gibel carp [13-15, 36]. The newly formed gibel carp with unisexual gynogynetic ability, might enter evolutionary trajectory of diploidization, as diploidization process after polyploidy was suggested to be the driving force of recurrent polyploidy $[13,37,38]$. Perhaps, it is the two rounds of polyploidy and diploidization as major evolutionary force that leads to different sex determination mechanisms of GSD and TSD, and acquires facultative reproduction strategies of unisexual and bisexual reproduction modes in the extant hexaploid gibel carp.

TSD is the most common system in ESD and occurs in very many reptiles $[5,11]$, some fishes $[39,40]$ and amphibians $[11,41]$. In gibel carp, males of TSD trigger typical unisexual gynonenesis (Figs. 3, 4 and 7) which is able to achieve high fecundity [42], but TSD is commonly considered to be particularly vulnerable to climate change [43, 44]. Compared with TSD, males of GSD in gibel carp, which are able to stimulate reproduction mode similar to bisexual reproduction (Figs. 3, 4 and 7), should have more genetic contribution to the offspring than males of TSD (Fig. 3). And the proportions of GSD is much higher than that of TSD in sympatric population across mainland China [9]. Although some unisexual vertebrates have widespread ecological distribution and long existence scale, unisexual reproduction is suggested to be invariable failure as a long-term evolutionary strategy [45], that might be why most species reproduce by obligate bisexual reproduction $[16,42]$. Thus, the hexaploid gibel carp might be also under the reproduction mode transition from unisexual gynogenesis to bisexual reproduction for a long evolutionary term $[13,19,21]$, and males of GSD with the ability to stimulate reproduction mode similar to bisexual reproduction in the 


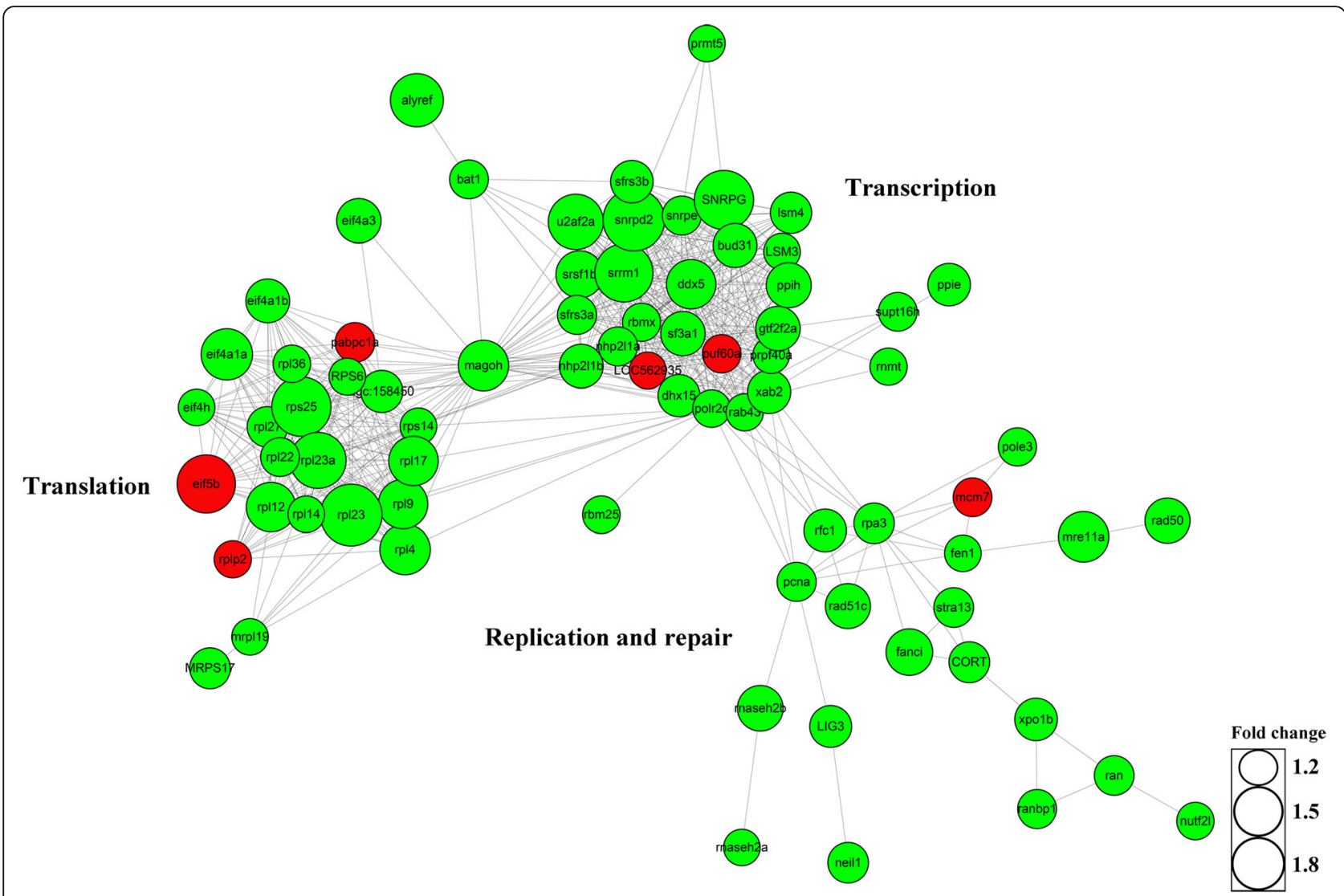

Fig. 8 Network analysis for DEPs assigned to "Replication and repair", "Translation" and "Transcription". The fold changes of DEPs are presented with different size. Green color indicates down-regulated DEPS, while red color indicates up-regulated DEPS

unisexual species might have more selective benefits than males of TSD with the ability to trigger unisexual gynogenesis.

\section{Conclusion}

We have screened variations between males of GSD and TSD in gynogenetic gibel carp, and revealed that DNA replication and gene expression-related pathways are associated with the distinct male nucleus development behaviors in fertilized eggs in response to the sperm from males of GSD and TSD, which might help us with understanding evolutionary adaption of diverse sex determination mechanisms in unisexual vertebrates.

\section{Methods}

\section{Experimental animal source}

All experimental fish including gibel carp (C. gibelio) and common carp (C. carpio) were collected from Wuhan Guanqiao Experimental Station, Institute of Hydrobiology, Chinese Academy of Sciences. Strain $\mathrm{A}^{+}$[46] of gibel carp and red common carp were used for the analyses in this study. The phenotypic sex of these fish were distinguished based on whether they ovulated and released eggs or produced sperm in the breeding season. Males of GSD were distinguished from males of TSD via the male-specific marker (MSM) identified previously [21].

\section{Artificial propagation and fish culture}

In the breeding season of gibel carp, the selected maternal fish were induced into spawning by intraperitoneal injection as described previously [47]. About $8-10 \mathrm{~h}$ after injection, the maternal fish started to ovulate, and the ovulated eggs were inseminated with sperms from gibel carp or red common carp. The embryos were incubated in culture dishes at $23^{\circ} \mathrm{C}\left( \pm 1{ }^{\circ} \mathrm{C}\right)$ during the periods of embryogenesis and larval hatching, and then the hatched larvae were reared at $20^{\circ} \mathrm{C}\left( \pm 1{ }^{\circ} \mathrm{C}\right)$ in water boxes equipped with an inflator pump. The larvae were fed with fairy shrimp for $35 \mathrm{~d}$ since first feeding and then maintained in outdoor tanks $(5 \mathrm{~m} \times 4 \mathrm{~m} \times 1.5 \mathrm{~m})$ with normal feed.

To produce males of TSD, the embryos of gynogenetic family were firstly incubated in culture dishes at $23{ }^{\circ} \mathrm{C}$ $\left( \pm 1{ }^{\circ} \mathrm{C}\right)$ until first feeding, and then the larval rearing temperature were gradually changed to $32{ }^{\circ} \mathrm{C}\left( \pm 1{ }^{\circ} \mathrm{C}\right)$ as previously described [9]. The larvae were reared in water boxes equipped with inflator pump during the larval rearing period for $35 \mathrm{~d}$. At last the fry were also maintained in outdoor tanks with normal feed. 


\section{Haematoxylin-eosin and immunofluorescence staining} The testes were dissected from males of GSD and males of TSD, and fixed in 4\% paraformaldehyde in PBS overnight at $4{ }^{\circ} \mathrm{C}$. Then samples were dehydrated and embedded in paraffin, and were cut into $5 \mu \mathrm{m}$ sections. HE staining was performed as previously described [48] and immunofluorescence staining using $C g$ Vasa antibody was performed as described [49].

\section{Scanning electron microscope and transmission electron microscopy}

The semen was fixed in PBS buffer $(\mathrm{pH}=7.4)$ containing $2.5 \%$ glutaraldehyde overnight at $4{ }^{\circ} \mathrm{C}$, and the fixed sperm specimens were dropped onto a tiny microslide. Then a stepwise ethanol dehydration $(10,30,50,70,80,90,100$, $100 \%, 10$ min each step) and a stepwise tert-butyl alcohol dehydration (tert-butyl alcohol: ethanol $=1: 3$, tert-butyl alcohol: ethanol $=1: 1$, tert-butyl alcohol: ethanol $=3: 1,100 \%$ tert-butyl alcohol, $10 \mathrm{~min}$ each step) were performed orderly. After electric conduction treatment, a S-4800 scanning electron microscope (SEM) (Hitachi High-Tech) was used to examine the sperm. Head width and tail length of the sperm were measured by SEM and ImageJ software [50]. In this study, 31 sperm from 3 males of GSD and 59 sperm from 3 males of TSD were measured for sperm head width detection, and 39 sperm from 3 males of GSD and 37 sperm from 3 males of TSD were measured for sperm tail length detection. The unpaired T-test was used to estimate the significant difference between sperm from males of GSD and TSD via SPSS software v19.0.0.

For transmission electron microscopy (TEM), the fixed sperm samples were washed in PBS and incubated with PBS containing $1 \%$ OsO4. Then the samples were treated with 50, 70, 80, 90 and 95\% ethanol orderly and processed with a mixed solution of acetone and epoxy resin (1:1 for $1 \mathrm{~h}$, and then 1:3 for $3 \mathrm{~h}$ ). After infiltration with epoxy resin and ultrathin-section treatment, the samples were stained with uranyl acetate and lead citrate. The specimens were observed with a HT7700 transmission electron microscope (Hitachi High-Tech).

\section{Analysis of sperm vitality and hatchability}

The semen was diluted 500 times by Hank's solution, then $10 \mu \mathrm{l}$ diluted semen was dropped onto on a glass slide. The prepared samples were observed and tested under a computer assisted sperm analyzer (CASA) system as soon as the sperm was activated by dropping $1 \mu \mathrm{l}$ water. The parameters of sperm motility and kinematics were assessed by Animal Motility Software Manual Version 1.4. And 61,163 sperms from 3 males of GSD and 83,516 sperms from 3 males of TSD were detected in total.

The ovulated eggs of maternal gibel carp were inseminated with sperm from males of GSD and TSD, and the embryos were incubated in culture dishes at $23^{\circ} \mathrm{C}\left( \pm 1^{\circ}\right.$
C) during the periods of embryogenesis and larval hatching. The hatchability was calculated as described [51], that hatchability = (the number of hatched larvae / the number of all fertilized eggs) $\times 100 \%$. The unpaired T-test was used to estimate the significant difference of sperm vitality and hatchability between males of GSD and TSD via SPSS software v19.0.0.

\section{DAPI staining in fertilized eggs}

The ovulated eggs of the females from strain $\mathrm{A}^{+}$in gibel carp were inseminated by sperms from males of GSD in strain $\mathrm{A}^{+}$, from males of TSD in strain $\mathrm{A}^{+}$, and from another species common carp. The fertilized eggs were digested by $0.25 \%$ trypsin to remove their shells and then incubated at $23{ }^{\circ} \mathrm{C}$ for cytological observations. The fertilized eggs of different developmental stage were fixed with $4 \%$ paraformaldehyde in PBS at $4{ }^{\circ} \mathrm{C}$ overnight. After washing with $\mathrm{PBS}$ three times, the nuclei were stained by DAPI, and the images were acquired under confocal microscopy (NOL-LSM 710 Carl Zeiss) as described [19].

\section{iTRAQ-based quantitative proteomics}

Total proteins of 6 semen samples from 3 males of GSD and 3 males of TSD in strain $\mathrm{A}^{+}$were extracted respectively as described before $[52,53]$, and the protein samples were quantified by Bradford Assay and SDS-PAGE analysis. The extracted proteins were digested using Trypsin Gold (Promega) after being diluted by $100 \mathrm{mM}$ triethylamine borane. Then peptides were labeled using iTRAQ Reagent8-plex Kit (AB SCIEX) according to the manufacturer's protocol [54]. The labeled peptides with different reagents were combined and desalted with a Strata X C18 column (Phenomenex) and vacuum-dried. Subsequently, the peptides were separated on a LC-20AB HPLC Pump system (Shimadzu), and the LC-MS/MS analysis was carried out as described [55].

The raw MS/MS data was converted into MGF format by ProteoWizard tool msConvert, the exported MGF files were searched in National Center for Biotechnology Information (NCBI) (https://www.ncbi.nlm.nih.gov/) and the Universal Protein Resource (UniProt) (http://www.uniprot.org/) using MASCOT version 2.3.02 (Matrix Science) and at least one unique peptide was necessary for the identified protein. Gene Ontology (GO) database (http://www.geneontology.org/) [56], Clusters of Orthologous Groups of proteins (COG) database (http://www.ncbi.nlm.nih.gov/ COG/) [57] and Kyoto Encyclopedia of Genes and Genomes (KEGG) database (http://www.genome.jp/kegg/ pathway.html) [58] were used for analysis.

\section{Identification of differentially expressed proteins}

Automated software IQuant were used for protein quantification as previously reported [59]. The peptide-spectral match (PSM) was pre-filtered at a PSM-level false discovery 
rate (FDR) of $1 \%$ for assessing the confidence of peptides. In order to control the rate of false-positive at protein level, an protein FDR at $1 \%$ was estimated after protein inference (protein-level FDR $\leq 0.01$ ) [60]. Proteins with 1.2 fold change and $P$-value less than 0.05 were determined as differentially expressed proteins (DEPs).

\section{Reactome database overrepresentation and KEGG pathway enrichment}

Overrepresentation analyses were performed in the Reactome database (https://reactome.org/) using up-regulated DEPs and down-regulated DEPs. The $P$-value indicated the statistical significance of each hit pathway, the false discovery rate (FDR) was calculated for estimating the false positives via Benjamini-Hochberg approach in Reactome [61], FDR $<0.25$ showed the confidence of "possible" or "hypothesis", FDR $<0.05$ denoted statistical significance [26]. All DEPs were used to perform KEGG pathway enrichment analysis using cluster profiler in $\mathrm{R}$ via Fisher's exact test, $P<0.05$ were considered as statistical significance.

\section{BrdU incorporation and immunofluorescence detection}

BrdU (5-bromo-2-deoxy-uridine) dissolved in PBS with the concentration of $0.01 \mathrm{mg} / \mathrm{ml}$ was microinjected into eggs $(1 \mathrm{nl}$ each) within $10 \mathrm{~min}$ after fertilization. Then, the BrdU incorporation embryos were fixed in $4 \%$ formaldehyde, $0.25 \%$ glutaraldehyde, and $0.1 \%$ Triton X-100 in PBS at $4{ }^{\circ} \mathrm{C}$ overnight. After treating with $2 \mathrm{~N} \mathrm{HCl}$ for $30 \mathrm{~min}$, neutralization by $0.1 \mathrm{M}$ sodium borate $(\mathrm{pH}=8.5)$ and washing in PBST (PBS containing 0.1\% Triton X-100), the embryos were subjected to immunofluorescence detection according to standard protocols. Mouse $\alpha$-BrdU antibody was used as primary antibody, and Rhodamine conjugated goat anti-mouse IgG was used as secondary antibody. Images were acquired under confocal microscopy (NOL-LSM 710 Carl Zeiss) as described [19].

\section{Analysis of protein interaction network}

DEPs assigned to the process of "Replication and repair", "Translation" and "Transcription" were used to perform protein interaction network analysis via String (http:// string-db.org/). Amino acid sequences of DEPs were uploaded to the String server, and database of Danio rerio was selected. The threshold of minimum required interaction score was set to the highest confidence (score $=0.900)$, and the results were visualized by using software Cytoscape3.5.1 [62].

\section{Additional files}

Additional file 1: Table S1. Detail data of male incidence, related to Fig. 3. (DOC $34 \mathrm{~kb}$ )

Additional file 2: Table S2. All proteins identified by iTRAQ approach and their annotation information in 6 databases. (XLS $4444 \mathrm{~kb}$ )
Additional file 3: Table S3. Up-regulated DEPs (males of TSD vs males of GSD). (XLS $235 \mathrm{~kb}$ )

Additional file 4: Table S4. Down-regulated DEPs (males of TSD vs males of GSD). (XLS $243 \mathrm{~kb}$ )

Additional file 5: Table S5. Detailed data of the top 20 enriched KEGG pathways, related to Fig. 6b (XLS $40 \mathrm{~kb}$ )

Additional file 6: Table S6. DEPs assigned to the process of "Replication and repair", related to Fig. 6c. (XLS 28 kb)

Additional file 7: Table S7. DEPs assigned to the process of "Translation", related to Fig. 6d. (XLS $29 \mathrm{~kb}$ )

Additional file 8: Table S8. DEPs assigned to the process of "Transcription", related to Fig. 6e (XLS $27 \mathrm{~kb}$ )

Additional file 9: Table S9. Subcellular location of down-regulated DEPs assigned to the process of "Replication and repair", "Translation" and "Transcription". (XLS $35 \mathrm{~kb})$

\section{Abbreviations}

BrdU: 5-bromo-2-deoxy-uridine; CASA: computer assisted sperm analyzer; COG: Clusters of Orthologous Groups of proteins; DEPs: differentially expressed proteins; DO: dissolved oxygen; ESD: environmental sex determination; F: flagellum; FDR: false discovery rate; GO: Gene Ontology; GSD: genotypic sex determination; HE: haematoxylin-eosin; KEGG: Kyoto Encyclopedia of Genes and Genomes; M: mid-piece; MSM: male-specific marker; N: nucleus; NCBI: National Center for Biotechnology Information; NR: non-redundant protein; PBST: PBS containing $0.1 \%$ Triton X-100; PSM: peptide-spectral match; SEM: scanning electron microscope; TEM: transmission electron microscopy; TrEMBL: Translated EMBL Nucleotide Sequence Data Library; TSD: temperature-dependent sex determination; Uniprot: Universal Protein Resource; VAP: average path velocity; VCL: curvilinear velocity; VSL: straight-line velocity

\section{Acknowledgements}

We would like to thank You Duan for assistance in data analysis (Institute of Hydrobiology, Chinese Academy of Sciences). We would like also to thank Fang Zhou for providing confocal services, and Zhen-Fei Xing and Yuan Xiao for providing SEM and TEM services (Analytical \& Testing Center, Institute of Hydrobiology, Chinese Academy of Sciences).

\section{Funding}

This work was supported by the Key Program of Frontier Sciences of the Chinese Academy of Sciences (QYZDY-SSW-SMC025), the National Natural Science Foundation of China (31502148), the Strategic Priority Research Program of the Chinese Academy of Sciences (XDA08030201), the Young Elite Scientist Sponsorship Program by CAST (YESS20150156), the Earmarked Fund for Modern Agro-industry Technology Research System (NYCYTX-49), the Autonomous Project of the State Key Laboratory of Freshwater Ecology and Biotechnology (2016FBZ01), the Autonomous Project of the Institute of Hydrobiology, Chinese Academy of Sciences (Y25A171) and the Knowledge Innovation Program of the Chinese Academy of Science. The funding bodies had no role in the design of the study and collection, analysis, and interpretation of data and in writing the manuscript.

\section{Availability of data and materials}

The proteomics raw data that support the findings of this study was submitted to the Proteomics Identifications Database (PRIDE) under the project accession number PXD008919.

\section{Authors' contributions}

$J F G, X Y L$ and $Y J Z$ conceived this project. YJZ, JZ, XYL, ZL and MD performed the experiments. YJZ, XYL, LZ and XJZ analyzed the data. JFG, XYL and YJZ wrote the manuscript. All authors read and approved the manuscript.

\section{Ethics approval and consent to participate}

Gibel carp (C. gibelio) and common carp (C. carpio) included in our experiment were collected from Wuhan Guanqiao Experimental Station, Institute of Hydrobiology, Chinese Academy of Sciences. All experiments in the study were carried out according to the regulations of the Guide for Care and Use of Laboratory Animals approved by the Animal Care and Use Committee of the Institute of Hydrobiology, Chinese Academy of Sciences. 


\section{Competing interests}

The authors declare that they have no competing interests.

\section{Publisher's Note}

Springer Nature remains neutral with regard to jurisdictional claims in published maps and institutional affiliations.

\section{Received: 14 February 2018 Accepted: 24 May 2018 Published online: 05 June 2018}

\section{References}

1. Bachtrog D, Mank JE, Peichel CL, Kirkpatrick M, Otto SP, Ashman TL, et al. Sex determination: why so many ways of doing it? PLoS Biol. 2014;12: e1001899.

2. Capel B. Vertebrate sex determination: evolutionary plasticity of a fundamental switch. Nat Rev Genet. 2017;18:675-89.

3. Mei J, Gui J-F. Genetic basis and biotechnological manipulation of sexual dimorphism and sex determination in fish. Sci China Life Sci. 2015;58:124-36.

4. Gamble T, Zarkower D. Sex determination. Curr Biol. 2012;22:R257-62.

5. Holleley CE, Omeally D, Sarre SD, Marshall Graves JA, Ezaz T, Matsubara K, et al. Sex reversal triggers the rapid transition from genetic to temperaturedependent sex. Nature. 2015:523:79-82

6. Brown EE, Baumann $\mathrm{H}$, Conover DO. Temperature and photoperiod effects on sex determination in a fish. J Exp Mar Biol Ecol. 2014:461:39-43.

7. Warner RR, Fitch DL, Standish JD. Social control of sex change in the shelf limpet, Crepidula norrisiarum: size-specific responses to local group composition. J Exp Mar Biol Ecol. 1996;204:155-67.

8. Baroiller JF, D'Cotta H, Saillant E. Environmental effects on fish sex determination and differentiation. Sex Dev. 2009:3:118-35.

9. Li X-Y, Liu X-L, Zhu Y-J, Zhang J, Ding M, Wang M-T, et al. Origin and transition of sex determination mechanisms in a gynogenetic hexaploid fish. Heredity. 2018; https://doi.org/10.1038/s41437-017-0049-7.

10. Shao C, Li Q, Chen S, Zhang P, Lian J, Hu Q, et al. Epigenetic modification and inheritance in sexual reversal of fish. Genome Res. 2014;24:604-15.

11. Sarre SD, Ezaz T, Georges A. Transitions between sex-determining systems in reptiles and amphibians. Annu Rev Genomics Hum Genet. 2011;12:391-406.

12. Gao Y, Wang S, Luo J, Murphy RW, Du R, Wu S, et al. Quaternary palaeoenvironmental oscillations drove the evolution of the Eurasian Carassius auratus complex (Cypriniformes, Cyprinidae). J Biogeogr. 2012;39:2264-78.

13. Liu X-L, Jiang F-F, Wang Z-W, Li X-Y, Li Z, Zhang X-J, et al. Wider geographic distribution and higher diversity of hexaploids than tetraploids in Carassius species complex reveal recurrent polyploidy effects on adaptive evolution. Sci Rep. 2017;7:5395

14. Liu X-L, Li X-Y, Jiang F-F, Wang Z-W, Li Z, Zhang X-J, et al. Numerous mitochondrial DNA haplotypes reveal multiple independent polyploidy origins of hexaploids in Carassius species complex. Ecol Evol. 2017;7:10604-15.

15. Li X-Y, Zhang X-J, Li Z, Hong W, Liu W, Zhang J, et al. Evolutionary history of two divergent Dmrt1 genes reveals two rounds of polyploidy origins in gibel carp. Mol Phylogenet Evol. 2014;78:96-104.

16. Neaves WB, Baumann P. Unisexual reproduction among vertebrates. Trends Genet. 2011;27:81-8.

17. Gui J-F, Zhou L. Genetic basis and breeding application of clonal diversity and dual reproduction modes in polyploid Carassius auratus gibelio. Sci China Life Sci. 2010;53:409-15.

18. Jiang F-F, Wang Z-W, Zhou L, Jiang L, Zhang X-J, Apalikova OV, et al. High male incidence and evolutionary implications of triploid form in Northeast Asia Carassius auratus complex. Mol Phylogenet Evol. 2013;66:350-359.

19. Zhang J, Sun M, Zhou L, Li Z, Liu Z, Li X-Y, et al. Meiosis completion and various sperm responses lead to unisexual and sexual reproduction modes in one clone of polyploid Carassius gibelio. Sci Rep. 2015;5:10898.

20. Zhou L, Wang Y, Gui J-F. Genetic evidence for gonochoristic reproduction in gynogenetic silver crucian carp (Carassius auratus gibelio Bloch) as revealed by RAPD assays. J Mol Evol. 2000;51:498-506.

21. Li X-Y, Zhang Q-Y, Zhang J, Zhou L, Li Z, Zhang X-J, et al. Extra microchromosomes play male determination role in polyploid gibel carp. Genetics. 2016:203:1415-24.

22. Amaral A, Castillo J, Ramalhosantos J, Oliva R. The combined human sperm proteome: cellular pathways and implications for basic and clinical science. Hum Reprod Update. 2014;20:40-62.
23. Croft D, O'Kelly G, Wu G, Haw R, Gillespie M, Matthews L, et al. Reactome: a database of reactions, pathways and biological processes. Nucleic Acids Res. 2011;39:691-7.

24. Fabregat A, Sidiropoulos K, Garapati P, Gillespie M, Hausmann K, Haw R, et al. The Reactome pathway knowledgebase. Nucleic Acids Res. 2014;42: D472-7.

25. Hancock REW, Haney EF, Gill EE. The immunology of host defence peptides: beyond antimicrobial activity. Nat Rev Immunol. 2016;16:321-34.

26. Kim HN, Kim BH, Cho J, Ryu S, Shin H, Sung J, et al. Pathway analysis of genome-wide association datasets of personality traits. Genes Brain Behav. 2015:14:345-56.

27. Nynca J, Arnold GJ, Fröhlich T, Otte KA, Flenkenthaler F, Ciereszko A. Proteomic identification of rainbow trout seminal plasma proteins. Proteomics. 2014;14:133-40.

28. Dietrich MA, Arnold GJ, Nynca J, Fröhlich T, Otte KA, Ciereszko A. Characterization of carp seminal plasma proteome in relation to blood plasma. J Proteome. 2014:98:218-32.

29. Nynca J, Arnold GJ, Fröhlich T, Otte KA, Ciereszko A. Proteomic identification of rainbow trout sperm proteins. Proteomics. 2014;14:1569-73.

30. Sonneville R, Craig G, Labib K, Gartner A, Blow JJ. Both chromosome decondensation and condensation are dependent on DNA replication in C. elegans embryos. Cell Rep. 2015;12:405-17.

31. Xu Y-N, Cui X-S, Sun S-C, Jin Y-X, Kim N-H. Cross species fertilization and development investigated by cat sperm injection into mouse oocytes. J Exp Zool. 2011;315:349-57.

32. Xu Y-N, Cui X-S, Tae J-C, Jin Y-X, Kim N-H. DNA synthesis and epigenetic modification during mouse oocyte fertilization by human or hamster sperm injection. J Assist Reprod Genet. 2011;28:325-33.

33. Zhang Z, Chen J, Li L, Tao M, Zhang C, Qin Q, et al. Research advances in animal distant hybridization. Sci China Life Sci. 2014:57:889-902.

34. Liu S-J, Liu Y, Zhou G-J, Zhang X-J, Luo C, Feng H, et al. The formation of tetraploid stocks of red crucian carp $\times$ common carp hybrids as an effect of interspecific hybridization. Aquaculture. 2001;192:171-86.

35. Li C-J, Gui J-F. Comparative studies on in vitro sperm decondensation and pronucleus formation in egg extracts between gynogenetic and bisexual fish. Cell Res. 2003:13:159-69.

36. Luo J, Gao Y, Ma W, Bi X-Y, Wang S-Y, Wang J, et al. Tempo and mode of recurrent polyploidization in the Carassius auratus species complex (Cypriniformes, Cyprinidae). Heredity. 2014;112:415-27.

37. Soltis PS, Marchant DB, Van de Peer Y, Soltis DE. Polyploidy and genome evolution in plants. Curr Opin Genet Dev. 2015;35:119-25.

38. Wendel JF. The wondrous cycles of polyploidy in plants. Am J Bot. 2015;102: $1753-6$.

39. Shen Z-G, Wang H-P. Molecular players involved in temperature-dependent sex determination and sex differentiation in teleost fish. Genet Sel Evol. 2014;46:26.

40. Yamamoto $Y$, Zhang $Y$, Sarida M, Hattori RS, Strussmann CA. Coexistence of genotypic and temperature-dependent sex determination in Pejerrey Odontesthes bonariensis. PLoS One. 2014:9:e102574.

41. Wallace $H$, Badawy GMI, Wallace BMN. Amphibian sex determination and sex reversal. Cell Mol Life Sci. 1999:55:901-9.

42. Burke NW, Bonduriansky R. Sexual conflict, facultative asexuality, and the true paradox of sex. Trends Ecol Evol. 2017:32:646-652.

43. Boyle M, Hone J, Schwanz LE, Georges A. Under what conditions do climate-driven sex ratios enhance versus diminish population persistence? Ecol Evol. 2014;4:4522-33.

44. Patinomartinez J, Marco A, Quinones L, Hawkes LA. A potential tool to mitigate the impacts of climate change to the caribbean leatherback sea turtle. Glob Chang Biol. 2012;18:401-11.

45. Avise JC. Evolutionary perspectives on clonal reproduction in vertebrate animals. Proc Natl Acad Sci U S A. 2015;112:8867-73.

46. Wang Z-W, Zhu H-P, Wang D, Jiang F-F, Guo W, Zhou L, et al. A novel nucleo-cytoplasmic hybrid clone formed via androgenesis in polyploid gibel carp. BMC Res Notes. 2011:4:82

47. Sun M, Li Z, Gui J-F. Dynamic distribution of spindlin in nucleoli, nucleoplasm and spindle from primary oocytes to mature eggs and its critical function for oocyte-to-embryo transition in gibel carp. J Exp Zool A Ecol Genet Physiol. 2010;313:461-73.

48. Xia W, Zhou L, Yao B, Li C-J, Gui J-F. Differential and spermatogenic cellspecific expression of DMRT1 during sex reversal in protogynous hermaphroditic groupers. Mol Cell Endocrinol. 2007;263:156-72. 
49. Xu H-Y, Gui J-F, Hong Y-H. Differential expression of vasa RNA and protein during spermatogenesis and oogenesis in the gibel carp (Carassius auratus gibelio), a bisexually and gynogenetically reproducing vertebrate. Dev Dyn. 2005:233:872-82.

50. Kowal J, Arras G, Colombo M, Jouve M, Morath JP, Primdal-Bengtson B, et al. Proteomic comparison defines novel markers to characterize heterogeneous populations of extracellular vesicle subtypes. Proc Natl Acad Sci U S A. 2016; 113:E968-77.

51. Unuma T, Kondo S, Tanaka H, Kagawa H, Nomura K, Ohta H. Determination of the rates of fertilization, hatching and larval survival in the Japanese eel, Anguilla japonica, using tissue culture microplates. Aquaculture. 2004;241: $345-56$.

52. Saravanan RS, Rose JKC. A critical evaluation of sample extraction techniques for enhanced proteomic analysis of recalcitrant plant tissues. Proteomics. 2004:4:2522-32.

53. Yao Y, Yang Y-W, Liu J-Y. An efficient protein preparation for proteomic analysis of developing cotton fibers by 2-DE. Electrophoresis. 2006;27:4559-69.

54. Chu P, Yan G-X, Yang Q, Zhai L-N, Zhang C, Zhang F-Q, et al. iTRAQ-based quantitative proteomics analysis of Brassica napus leaves reveals pathways associated with chlorophyll deficiency. J Proteome. 2015;113:244-59.

55. Chen T, Zhang L, Shang H, Liu S, Peng J, Gong W, et al. iTRAQ-based quantitative proteomic analysis of cotton roots and leaves reveals pathways associated with salt stress. PLoS One. 2016;11:e0148487.

56. Conesa A, Götz S, García-Gómez JM, Terol J, Talón M, Robles M. Blast2GO: a universal tool for annotation, visualization and analysis in functional genomics research. Bioinformatics. 2005;21:3674-6.

57. Tatusov RL, Koonin EV, Lipman DJ. A genomic perspective on protein families. Science. 1997;278:631-7.

58. Wu J, Mao X, Cai T, Luo J, Wei L. KOBAS server: a web-based platform for automated annotation and pathway identification. Nucleic Acids Res. 2006; 34:W720-4.

59. Wen B, Zhou R, Feng Q, Wang Q, Wang J, Liu S. IQuant: an automated pipeline for quantitative proteomics based upon isobaric tags. Proteomics. 2014;14:2280-5.

60. Savitski MM, Wilhelm M, Hahne H, Kuster B, Bantscheff M. A scalable approach for protein false discovery rate estimation in large proteomic data sets. Mol Cell Proteomics. 2015:14:2394-404.

61. Fabregat A, Sidiropoulos K, Viteri G, Forner O, Marin-Garcia P, Arnau V, et al. Reactome pathway analysis: a high-performance in-memory approach. BMC Bioinformatics. 2017;18:142

62. Zeng W, Sun Z, Cai Z, Chen H, Lai Z, Yang S, et al. Proteomic analysis by ITRAQ-MRM of soybean resistance to Lamprosema Indicate. BMC Genomics. 2017;18:444

\section{Ready to submit your research? Choose BMC and benefit from:}

- fast, convenient online submission

- thorough peer review by experienced researchers in your field

- rapid publication on acceptance

- support for research data, including large and complex data types

- gold Open Access which fosters wider collaboration and increased citations

- maximum visibility for your research: over $100 \mathrm{M}$ website views per year

At BMC, research is always in progress.

Learn more biomedcentral.com/submissions 